\title{
Information provided to customers about over-the-counter medications dispensed in community pharmacies in Libya: a cross- sectional study
}

\author{
Ahmed Atia ${ }^{1}$
}

${ }^{1}$ Department of Anaesthesia and Intensive Care, Faculty of Medical Technology, Tripoli University, Tripoli, Libya (Correspondence to Ahmed Atia: elbadri83@yahoo.com).

\begin{abstract}
Background: Adherence to pharmacy practice guidelines for dispensing medications in pharmacy settings is important to ensure the safe use of medications.

Aims: This study assessed the pattern and adequacy of information given to consumers on over-the-counter medications dispensed in community pharmacies in Tripoli, Libya, and compared the performance of pharmacists and non-pharmacists.

Methods: This was a cross-sectional survey of private community pharmacies conducted in 2018 . Trained simulated patients were used to collect data on over-the-counter medications dispensed for hypothetical common cold symptoms and the information given by the pharmacy staff on the medication. This information included: name and the strength of the medication, indication for use, duration of use, dosage, how often to take the medicine, timing (before/after/with food), storage, expiry date, and side-effects of the medicine. Time taken to deliver the information was recorded. The adequacy of information provided by the pharmacists and non-pharmacists was compared.

Results: A total of 169 pharmacies were surveyed. There were no significant differences between pharmacists and non-pharmacists in information given on the dispensed medications, except for information on taking the medication with food or not $(84.5 \%$ of pharmacists gave this information versus $57.1 \%$ of non-pharmacists; $P=0.001)$ and on potential side-effects $(39.4 \%$ of pharmacists versus $20.3 \%$ of non-pharmacists; $P=0.014)$. Significantly more pharmacists $(85.9 \%)$ than non-pharmacists $(61.2 \%)$ provided the medication-related information in less than 1 minute $(P=0.001)$.

Conclusion: The inadequate information on medications provided by pharmacists is a concern for patient safety. Health regulatory organizations need to promote safe medication practices.

Keywords: pharmacies, pharmacists, patient safety, dispensing, Libya

Citation: Atia A. Information provided to customers about over-the-counter medications dispensed in community pharmacies in Libya: a cross-sectional study. East Mediterr Health J. 2020;26(7):828-833. https://doi.org/10.26719/emhj.20.030

Received: 06/06/18; accepted: 14/10/18

Copyright (c) World Health Organization (WHO) 2020. Open Access. Some rights reserved. This work is available under the CC BY-NC-SA 3.0 IGO license (https://creativecommons.org/licenses/by-nc-sa/3.o/igo)
\end{abstract}

\section{Introduction}

Good dispensing practices ensure that the medicine are given to consumers with detailed directions to prevent the occurrence of medication errors (1). However, there is considerable evidence of poor dispensing practices in pharmacies and inadequate information and advice given on the use of the prescribed medicines in developing countries (1). Accurate information about the name of a medication and directions for use should be provided to consumers, particularly for over-the-counter medications. Such dispensing practice is one of the most important sources of information available to consumers (2). The medication instruction given to consumers by community pharmacists may be inadequate or difficult for the consumer to understand. Lack of appropriate information on medication given to consumers is a potential cause of medication errors $(3,4)$.

There is an increasing demand for consumers to selfmedicate with non-prescription medications for common illnesses and pharmacy personnel are the health care specialists available who have knowledge of drug safety and rational use of medications (5-7).
According to the American Pharmacists Association, pharmaceutical care should be patient-centred and outcomes-oriented, rather than medication-centred, which requires pharmacists to take responsibility as direct care providers for patients. Thus, proper instruction when dispensing medication by community pharmacists could prevent the incidence of medication errors and probably reduce hospitalization rates among consumers $(8,9)$.

In Libya, medicines for symptoms of the common cold, such as decongestants and antihistamines, can be sold by community pharmacists as a dispensed medicine without the need for a prescription from a doctor (10). Hence, the objective of this study was to explore the quality and quantity of information provided by pharmacists to consumers when dispensing over-thecounter medications.

\section{Methods}

\section{Study design and sample}

This was an exploratory cross-sectional study conducted from February to May 2018 in Tripoli, Libya. 
For the purpose of this study, 169 private community pharmacies in the city of Tripoli were visited based on their accessibility to the researchers. The sample size was estimated using an online calculator (confidence interval of 3, and margin of error of 95\%) (11). Of the 169 pharmacy staff members who assisted the simulated patient, 71 were qualified pharmacists and 98 were nonpharmacists.

\section{Data collection}

A simulated patient method was used, involving $13 \mathrm{sev}$ enth semester undergraduate pharmacy students from Tripoli University who visited selected private community pharmacies in the city of Tripoli; each student visited 13 pharmacies. The students were trained as simulated patients and instructed to report having common cold symptoms at the pharmacies to assess the medication dispensing practices of the staff. The case scenario used for this study was that of a 22 -year-old female patient who presented to the pharmacy with primary symptoms of a common cold (sneezing, runny nose, no cough or sore throat) for the past few day, and was visiting the pharmacy to request a sedative medication for her symptoms. The reason for requesting sedative antihistamine was because it is cheaper than the second-generation non-sedative antihistamines such as desloratadine that are available in the Libyan pharmacies. The information presented by the simulate patient to the community pharmacy staff is shown in Table 1.

Data collected by the simulated patient during the pharmacy visit were recorded on a standardized data collection checklist. This checklist included five elements. The first three related to information that would be expected to be given to the consumer: name and the strength of the medication, information on the medication (indication for use, duration, dosage, frequency, timing (before or after food), storage and expiry date) and side-effects of the medicine. The remaining two were: qualification of pharmacy staff member consulted (pharmacist, non-pharmacist) and time taken to deliver the information.

For the first three elements, each type of information was assigned a score of " 1 " if delivered or " 0 " if not. We expected that the pharmacy staff would give the simulated patients the essential cautionary warnings, such as not to drive when taking this sedative medication.

\section{Data analysis}

Microsoft Excel, 2013 and SPSS, version 22.0 were used for data analysis. Descriptive statistics (frequencies and percentages) were recorded. The chi-squared test was used to compare the information given by the pharmacists versus non-pharmacists. The Mann-Whitney test was used to compare the time taken by the pharmacists and the non-pharmacists to give the information on the medication. A P-value less than 0.05 was considered statistically significant.

\section{Ethical considerations}

The study was approved by the Department of Pharmacy, University of Tripoli, Libya. All data gathered were kept confidential by the investigators. Because of the nature of the study, the pharmacies included in the study and their staff were not informed beforehand and hence had not given consent to participate.

\section{Results}

More non-pharmacists dispensed more than one medication $(62.2 \%, n=61)$ at the visited pharmacies than pharmacists did.

Most of the personnel in the pharmacies did not provide adequate information on the use of the dispensed medications to the simulated patient. As shown in Table 2, only 8 (11.3\%) pharmacists and 13 $(13.3 \%)$ non-pharmacists provided the simulated patient with the name and strength of medicines dispensed. However, 68 (95.8\%) pharmacists and 95 (96.9\%) nonpharmacists provided information on how often to take the medication. More pharmacists $(84.5 \%)$ than nonpharmacists $(57.1 \%)$ provided the simulated patient with information on when the medications should be taken (before, after or with food) $(P=0.001)$. Only $39.4 \%$ of the pharmacists and $20.3 \%$ of the non-pharmacists told the simulated patient about the side-effects of the medicine, although this was a statistically significant difference $(P=0.001)$. In addition, only about $40 \%$ of the pharmacists and non-pharmacists told the patients how long to take the medication for $(P=0.174)$. Very few pharmacists and non-pharmacists told the patients the expiry date of the medicine ( $8.4 \%$ and $10.2 \%$, respectively; $P=0.174$ ). None of the pharmacy personnel provided information on medication storage.

\section{Table 1 Simulated patient information for a common cold}

\begin{tabular}{|c|c|}
\hline Enquiry by pharmacy personnel & Simulated patient response \\
\hline Patient information & Female patient aged 22 years \\
\hline Symptoms & Sneezing and a runny nose and. No cough or sore throat \\
\hline Duration of symptoms & A few days \\
\hline Previous habit of using the requested medicine & $\begin{array}{l}\text { Previous use of a sedative drug which was good for a common cold. } \\
\text { Have forgotten the name of the product }\end{array}$ \\
\hline Used of any medication for the current symptoms & Nothing taken yet \\
\hline History of allergy & Not allergic to anything \\
\hline Other relevant medication? & Request a sedative medication \\
\hline
\end{tabular}




\begin{tabular}{|c|c|c|c|}
\hline \multirow[t]{2}{*}{ Information } & \multicolumn{2}{|c|}{ No. (\%) } & \multirow[t]{2}{*}{$P$-value } \\
\hline & Pharmacist $(n=71)$ & Non-pharmacist $(n=98)$ & \\
\hline Name and strength of medication & $8(11.3)$ & $13(13.3)$ & 0.943 \\
\hline \multicolumn{4}{|l|}{ Information on medication } \\
\hline Frequency of use & $68(95.8)$ & 95 (96.9) & 0.598 \\
\hline Duration & $29(40.8)$ & $41(41.8)$ & 0.174 \\
\hline Dosage & $37(52.1)$ & $57(58.2)$ & 0.321 \\
\hline Before or after food & $60(84.5)$ & $56(57.1)$ & 0.001 \\
\hline Indication & $31(43.7)$ & $47(48.0)$ & 0.785 \\
\hline Storage of medication & $0(0.0)$ & $0(0.0)$ & - \\
\hline Expiry date & $6(8.4)$ & $10(10.2)$ & 0.174 \\
\hline Side-effects & $28(39.4)$ & $22(22.4)$ & 0.001 \\
\hline
\end{tabular}

${ }^{a}$ Chi-square test; $P<0.05$ was considered statistically significant.

Most pharmacy personnel provided medicationrelated information to the simulated patient in less than 1 minute (Table 3 ) but a significantly greater proportion of pharmacists $(85.9 \%)$ took less than a minute than nonpharmacists $(61.2 \%)(P=0.001)$.

\section{Discussion}

This is the first study to examine the pattern and amount of medication-related information provided to consumers by pharmacists or non-pharmacists in Libyan private sector pharmacies. Most pharmacy personnel gave information on frequency of taking the medication. This is perhaps due to the awareness of community pharmacy staff that medication frequency is one of the most important pieces of information to be provided in the dispensing process to ensure that consumers take the medicine appropriately.

It is useful for pharmacy personnel to give the name and strength of the medication during dispensing (12). In our study, few of the personnel in the community pharmacies visited provided the simulated patient with this information (11.2\% and $13.2 \%$ of pharmacists and nonpharmacists, respectively). This finding is consistent with the results of studies conducted in 10 primary health care centres in Alexandria, Egypt and in 10 health centres in the eastern province of Saudi Arabia, where medication name and dose were not mentioned $(13,14)$. Medication name is a fundamental piece of information that should be given to consumers when they receive the drug, especially for non-prescription medication (15). Even though most of the over-the-counter medications dispensed in this study were in original packaging on which the name of the medication is printed, pharmacy personnel should still inform consumers what medication is actually given. Consumers should know the name of the medication they are taking so that if questioned by another pharmacy, they would be able to answer. This is to prevent consumers being given the same medication by different pharmacies, thus avoiding accidental medication errors.

The World Health Organization (WHO) recommends that each drug label should contain the dose regimen (how often to take the medicine), patient name and drug dose (drug concentration) (16). Consumer awareness of the correct dosage is important to avoid drug misuse and prevent adverse effects that would be harmful to the consumer's health (14). Only 37 (52.1\%) of our pharmacist participants and $57(58.1 \%)$ of the non-pharmacist participants provided this information to the simulated patient. A study conducted in Saudi Arabia reported that the frequency and number of doses were not stated in $6.9 \%$ and $7.6 \%$ of total prescriptions, respectively (17).

In spite of their essential role in pharmaceutical care, medicines can also be a substantial source of harm to consumers, either through preventable medication errors or non-preventable drug side-effects (18). Nevertheless, only $39.4 \%$ of pharmacists and $20.3 \%$ of non-pharmacists in our study mentioned the possible side-effects of the dispensed medication to the simulated patient. The poor instruction about adverse effects is similar to the results of a study in Ethiopia (19).

An average dispensing time of less than 60 seconds is considered to be insufficient by WHO criteria to clarify the dosage regimen and other instructions on the dispensed drugs (20). A consumer's understanding of

\begin{tabular}{|c|c|c|c|}
\hline \multirow[t]{2}{*}{ Length of time during dispensing } & Pharmacist $(n=71)$ & Non-pharmacist $(n=98)$ & \multirow[t]{2}{*}{ P-value ${ }^{a}$} \\
\hline & No. (\%) & No. (\%) & \\
\hline Less than 1 minute & $61(85.9)$ & $60(61.2)$ & \multirow{2}{*}{0.001} \\
\hline $1-5$ minutes & $10(14.1)$ & $38(38.8)$ & \\
\hline
\end{tabular}


a drug dispensed depends directly on their knowledge of the drug; therefore, sufficient dispensing time is an essential step in successful patient care (20). In the current study, the average consultation time of $85.9 \%$ of pharmacists and $61.2 \%$ of non-pharmacist was less than 60 seconds. Similarly, the average dispensing time of pharmacists reported in other developing countries was also low; 47.4 seconds in Egypt and 28.8 seconds in Jordan $(13,21)$.

The differences between the pharmacists and non-pharmacists visited in our study in providing the appropriate information when dispensing medication were statistically significant for potential drug-related side-effects and how the medications should be taken with regard to food. The pharmacists performed better that the non-pharmacists, even though more pharmacists spent less than a minute in dispensing the medication. Most of the non-pharmacists who work in private sector pharmacies in Libya have not taken a course on over-the-counter medicines or managing minor illnesses (22). Hence, it would be expected that pharmacists could supply more information when dispensing medicines. However, the adequacy of most of the required instruction given by pharmacists and non-pharmacists was not significantly different.

Our study has some limitations. The study was carried out in Tripoli, thus the setting was limited; no other Libyan cities were considered. In addition, only over-thecounter medications were considered. The study also did not investigate instructions related to allergies and concomitant therapies (drug-drug interactions).

The findings from this study show that most of the community pharmacists and non-pharmacists visited by the simulated patients delivered inadequate and inconsistent information on the dispensed medications and did not adhere to WHO recommendations (20). The Ministry of Health in Libya plans to educate and increase awareness among the community on dispensed medications (9). Therefore, this survey provides some initial data on medication-related information given to the public by community pharmacists. Governmental health care regulatory organizations need to play a strong and leading role in promoting safe medication practices and ensuring the enforcement of laws.

\section{Acknowledgment}

We thank all the pharmacists and students who participated in this study.

Funding: None.

Competing interests: None declared.

\section{Informations fournies aux clients lors de la distribution de médicaments en vente libre dans les pharmacies d'officine de Tripoli (Libye) : étude transversale}

\section{Résumé}

Contexte:Il est important de respecter les recommandations de pratique pharmaceutique en ce qui concerne la distribution de médicaments en pharmacie pour garantir une utilisation sûre des médicaments.

Objectifs : La présente étude visait à évaluer le profil et la qualité des informations fournies aux consommateurs au sujet des médicaments distribués en vente libre dans les pharmacies d'officine de Tripoli (Libye), puis à comparer les résultats entre les pharmaciens et les non-pharmaciens.

Méthodes : Elle a pris la forme d'une enquête transversale menée en 2018 auprès des pharmacies d'officine privées. Des personnes formées à simuler le rôle de patients ont permis de recueillir des données sur les médicaments distribués en vente libre pour d'hypothétiques symptômes de rhume, ainsi que sur les informations données par le personnel des pharmacies au sujet des médicaments. Ces informations comprenaient les éléments suivants : le nom et la concentration du médicament, l'usage indiqué, la durée d'utilisation, le dosage, la fréquence de prise du médicament et le moment approprié (avant, après ou pendant le repas), le stockage, la date d'expiration et les effets secondaires. Le temps consacré à la communication de ces informations a été enregistré. La qualité des informations fournies a été comparée entre les pharmaciens et les non-pharmaciens.

Résultats: Au total, 169 pharmacies ont été visitées dans le cadre de cette enquête. Aucune différence significative n'a été constatée entre les pharmaciens et les non-pharmaciens pour les informations données au sujet des médicaments distribués, à l'exception des explications concernant le moment où le médicament doit être pris par rapport au repas $(84,5 \%$ des pharmaciens ont donné cette information contre $57,1 \%$ des non-pharmaciens $; p=0,001)$ et les effets secondaires potentiels $(39,4 \%$ des pharmaciens contre $20,3 \%$ des non-pharmaciens; $p=0,014)$. Les pharmaciens $(85,9 \%)$ étaient nettement plus nombreux que les non-pharmaciens $(61,2 \%)$ à fournir les informations relatives aux médicaments en moins d'une minute $(p=0,001)$.

Conclusion : L'insuffisance des informations relatives aux médicaments fournies par les pharmaciens est une source de préoccupation pour la sécurité des patients. Les organismes de réglementation sanitaire doivent promouvoir des pratiques de médication sûres. 


\section{المعلومات التي تُقدم للعملاء عند صرف الأدوية التي تُباع دون وصفة طبية في الصيدليات المجتمعية في ليبيا: دراسة

الخلفية: من الضروري الالتزام بالمبادئ التوجيهية للممارسات الصيدلانية في ما يتعلق بصرف الأدوية من الصيدليات، وذلك لضمان الاستخدام المأمون للأدوية.

الأهداف: هدفت هذه الدراسة في تقييم نمط و كفاية المعلومات التي تُقدم إلى المستهلكين بشأن الأدوية التي تُباع دون وصفة طبية في الصيدليات

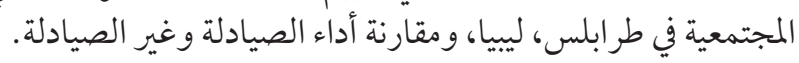

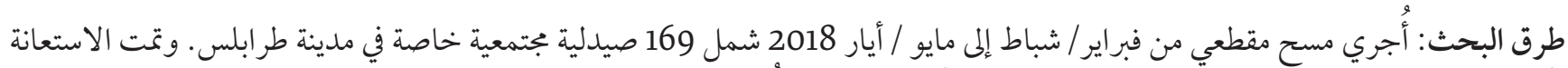

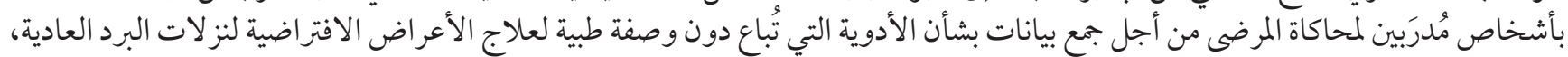

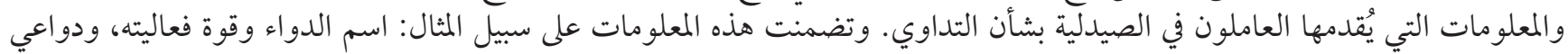

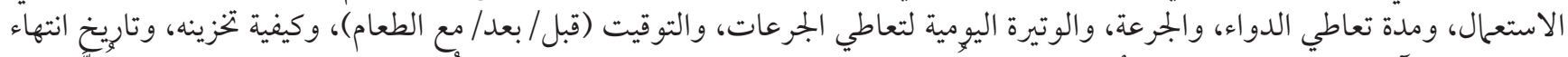

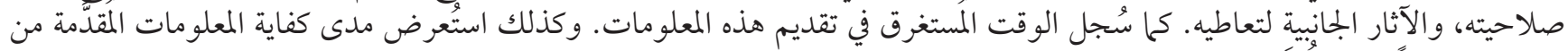

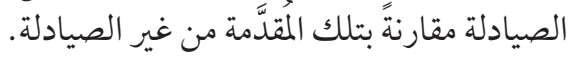

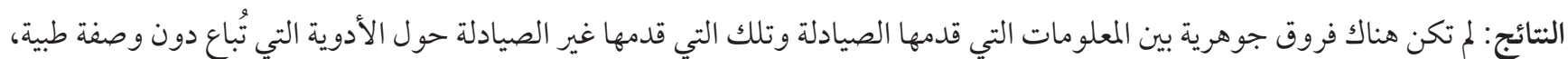

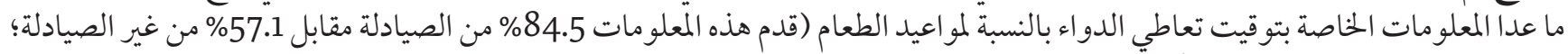

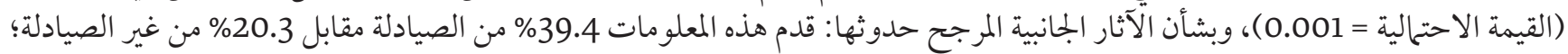

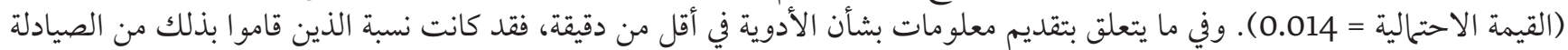

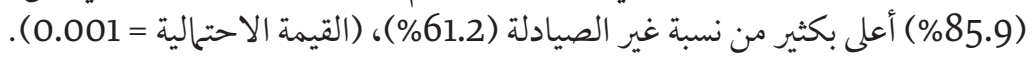

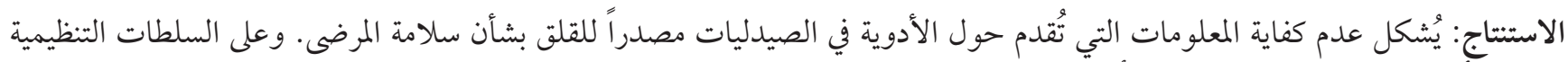

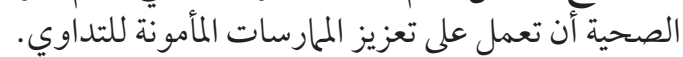

\section{References}

1. Miller R, Goodman C. Performance of retail pharmacies in low- and middle-income Asian settings: a systematic review. Health Policy Plan. 2016;31(7):940-53. https://doi.org/10.1093/heapol/czw007

2. Ngongoni R, Gan G, Deng Y, Agaba G, Akiteng A, Schwartz J. Prescribing and dispensing practices for medicines used to treat non-communicable diseases in Uganda: a cross-sectional study. Lancet. 2018;6:S23. https://doi.org/10.1016/S2214-109X(18)30152-9

3. Lyons I, Furniss D, Blandford A, Chumbley G, Iacovides I, Wei L, et al. Errors and discrepancies in the administration of intravenous infusions: a mixed methods multihospital observational study. BMJ Qual Saf. 2018;7(11):892-901 https://doi.org/10.1136/ bmjqs-2017-007476

4. Shrank W, Agnew-Blais J, Choudhry N, Wolf M, Kesselheim A, Avorn J, et al. The variability and quality of medication container labels. Arch Intern Med. 2007;167(16):1760-5. https://doi.org/10.1001/archinte.167.16.1760

5. Benrimoj S, Werner J, Raffaele C, Roberts A. A system for monitoring quality standards in the provision of non-prescription medicines from Australian community pharmacies. Pharm World Sci. 2008;30:147-153. https://doi.org/10.1007/s11096-007-9162-7.

6. Lonie J. From counting and pouring to caring: the empathic developmental process of community pharmacists. Res Social Adm Pharm. 2006;2(4):439-57. https://doi.org/10.1016/j.sapharm.2006.01.002

7. Fong DJ. Pharmacy trends for 2018. Wolters Kluwer; 18 December 2017 (http://www.wolterskluwercdi.com/blog/pharmacy-trends-2018/, accessed 30 May 2018).

8. Alsharif S, Khalf A, Sughir A, El-Attug M, Ammar A, Kamur R. Performance assessment of community pharmacist's intervention in quality of care in Tripoli, Libya: a cross-sectional study. Lebda Med J. 2016;2:61-4.

9. Atia A. Prescribing errors and the need for prescription separation in Libya. Libyan J Med Sci. 2018;2(1):1-2. https://doi. org/10.4103/LJMS.LJMS_48_17

10. Atia A, Abired A. Antibiotic prescribing for upper respiratory tract infections by Libyan community pharmacists and medical practitioners: an observational study. Libyan J Med Sci. 2017;1(2):31-5. https://doi.org/10.4103/LJMS.LJMS_14_17

11. National Statistical Service (https://www.abs.gov.au/websitedbs/d3310114.nsf/home/sample+size+calculator, accessed 29 May 2018).

12. Neoh C, Hassali M, Shafie A, Awaisu A. Nature and adequacy of information on dispensed medications delivered to patients 
in community pharmacies: a pilot study from Penang, Malaysia. J Pharm Health Serv Res. 2010;2(1):1-7. https://doi.org/10.1111/ j.1759-8893.2010.00026.x

13. Akl O, El Mahalli A, Elkahky A, Salem A. WHO/INRUD drug use indicators at primary healthcare centers in Alexandria. Egypt. J Taibah Univ Med Sci. 2014;9(1):54-64. https://doi.org/10.1016/j.jtumed.2013.06.002

14. El.Mahalli A, Akl O, Al-Dawood S, Al-Nehab A, Al-Kubaish H, Al-Saeed S, et al. WHO/INRUD patient care and facility specific drug use indicators at primary healthcare centers in Eastern Province, Saudi Arabia. Eastern Mediterr Health J. 2012;18(11):1086-90.

15. Neoh C, Hassali M, Shafie A, Awaisu A, Tambyappa J. Compliance towards dispensed medication labelling standards: a cross-sectional study in the state of Penang, Malaysia. Curr Drug Saf. 2009;4(3):199-203. https://doi.org/10.2174/157488609789006921

16. How to investigate drug use in health facilities: selected drug indicators. Geneva: World Health Organization; 1993 (https://apps. who.int/medicinedocs/pdf/s2289e/s2289e.pdf, accessed 28 December 2019).

17. Irshaid Y, Al Homrany M, Hamdi A, Adjepon K, Mahfouz A. Compliance with good practice in prescription writing at outpatient clinics in Saudi Arabia. East Mediterr Health J. 2005;11(5-6):922-8.

18. Britten N. Medication errors: the role of the patient. Br J Clin Pharmacol. 2009;67(6):646-50. https://doi.org/10.1111/j.13652125.2009.03421.X.

19. Wabe N, Raju N, Angamo M. Knowledge, attitude and practice of patient medication counselling among drug dispensers in north west Ethiopia. J Appl Pharm Sci. 2011;1(7):85-90.

20. Promoting rational use of medicines: core components. In: WHO policy perspectives on medicines, No. 5. Geneva: World Health Organization; 2002 (http://apps.who.int/medicinedocs/pdf/h3011e/h3011e.pdf, accessed 28 December 2019).

21. Otoom S, Batieha A, Hadidi H, Hasan M, Al-Saudi K. Evaluation of drug use in Jordan using WHO patient care and health facility indicators. East Mediterr Health J. 2002;8(4-5):544-9.

22. Sherif F. An evaluation of the prescribing patterns of drugs in Libya. Jamahiriya Med J. 2008;8(3):203-6. 